DOI: $10.17816 /$ ecogen $16224-29$

\title{
POLYMORPHISMS OF 5'-UTR OF RAD51 GENE IN PROSTATE CANCER
}

(C) M.S. Al-Zoubi ${ }^{1}$, K.M. Al-Batayneh ${ }^{1}$, B. Al-Trad ${ }^{1}$, M. Alorjani ${ }^{2}$, S. Al-Bashir ${ }^{2}$, R.M. Al-Zoubi ${ }^{2}$, S.M. Al-Khatib ${ }^{2}$, M. Al-Hamad ${ }^{3}$, M.A. Abd Al-Razaq ${ }^{1}$, R. Muhaidat ${ }^{1}$, I. Matalka ${ }^{2}$

\author{
${ }^{1}$ Yarmouk University, Irbid, Jordan; \\ ${ }^{2}$ Jordan University of Science and Technology, Irbid, Jordan; \\ ${ }^{3}$ Imam Abdulrahman Bin Faisal University, Dammam, Kingdom of Saudi Arabia
}

For citation: Al-Zoubi MS, Al-Batayneh KM, Al-Trad B, et al. Polymorphisms of 5'-UTR of RAD51 gene in prostate cancer. Ecological genetics. 2018;16(2):24-29. doi: 10.17816/ecogen 16224-29.

Received: 18.02 .2018

Accepted: 10.06 .2018

\begin{abstract}
Background. Notwithstanding that prostate cancer is largely studied all over the world for many decades, its etiology is not known and there is an intensive work to elucidate the cause and molecular markers for the development of this male cancer. Polymorphisms in DNA repairing genes may affect the DNA repairing capacity that in turn contributes to cancer development. This study aims to explore the polymorphisms of homologous recombination (HR) RAD51 gene (rs1801320 and rs1801321) as a possible risk factor for developing prostate cancer. Sequencing of 5'-UTR of RAD51 gene (rs1801320 and rs1801321) was studied in 80 DNA samples of prostate cancer and 50 DNA samples from a control group. Our results revealed a significant correlation between rs $1801320 \mathrm{G}>\mathrm{C}$ polymorphism and the presence of prostate cancer in the Jordanian population $\left(p=0.041, X^{2}=6.377\right)$. On the other hand, the rs 1801321 $\mathrm{G}>\mathrm{T}$ polymorphism was not associated with the presence of prostate cancer in the study population $\left(p=0.27, X^{2}=2.6\right)$. In conclusion, our results shed a light on the possible role of $R A D 51$ gene polymorphisms in the development of prostate cancer; however, a larger representative study is needed to elucidate a possible role of RAD51 gene polymorphisms in development and prognosis of prostate cancer.
\end{abstract}

Keywords: RAD51; 5'-UTR polymorphism; prostate cancer; rs1801320; rs1801321.

\section{INTRODUCTION}

Prostate cancer (PC) in Jordan, as the developed countries, is the most commonly diagnosed cancer in men. The incidence of prostate cancer in Jordan has increased in the last decades, and it shows a rise in the number of prostate cancer cases among Jordanian males from 123 in 2000 to 218 in 2010 [1]. As a heterogeneous type of cancer, prostate cancer has no identified susceptibility genes or etiologic agents [2-4]. However, some genetic loci have been studied in prostatic carcinoma including BRCA1, $B R C A 2, E L A C 2$, RNASEL and MSR1 genes [3]. Nevertheless, low penetrance of those genes was demonstrated in prostate cancer [5-7]. Therefore, many studies have investigated the possible association between the mutations or polymorphisms in DNA repair genes and the development of prostatic carcinoma [8].

Naturally, continuous exposure of cells to genotoxic factors can lead to DNA damage which, in turn, activates DNA repairing mechanisms. RAD51 is a homologous recombination (HR) protein that is encoded by RAD51 gene located on chromosome 15 [9]. RAD51 is a key recombinase in the process of double-strand breaks (DSBs) repair by homologous recombination; other accessory proteins are involved in the DSBs such as RAD51 family proteins and breast cancer associated proteins BRCA1 and BRCA2 [10, 11]. Genetic alteration in RAD51 has been shown to be related to cancer development by several studies [12-21]. For instance, RAD51 and RAD51-related proteins have been found to be overexpressed and deregulated in some types of cancers like colorectal, pancreatic and breast cancers [22-26]. Basically, mutations of RAD51 can lead to defects in mitotic and meiotic recombination, DSB repair and hypersensitivity to ionization [11, 27-30]. Genetic predisposition of DNA repairing proteins in cancer has been suggested after many studies of single nucleotide polymorphisms (SNPs) in certain genes like (RAD51, $X R C C 1, X R C C 2$ and XRCC3) [12, 16, 31-36]. A significant association has been found between breast cancer and polymorphic changes at G135C (rs1801320) and G172T (rs1801321) positions in the 5'-UTR region of the RAD51 gene [12,16,37]. Similarly, rs 1801320 and rs 1801321 polymorphisms of the $5^{\prime}$-UTR-RAD51 area have been investigated in many other cancers including prostate cancer [19, 38, 39].

The aim of the current case-control study was to elucidate a possible association between prostate cancer and G135C (rs1801320) and G172T (rs1801321) polymorphisms at the 5'-UTR area of the RAD51 gene in the Jordanian population. 


\section{MATERIALS AND METHODS}

Tumor Samples and Patients

Formalin Fixed Paraffin Embedded (FFPE) tissue samples from 80 prostate cancer patients who underwent prostatectomy were provided by the Department of Pathology at King Abdullah University Hospital from January 2003 through December 2016. Most of them had advanced stages of the disease (Table 1). The tissue diagnoses were submitted based on a pathologic assessment verified by a pathologist at the Department of Pathology. The majority of the samples showed tumor component of over $60 \%$. The mean age of the enrolled patients with prostate cancer was 72 years (range, $55-95$ years). The control group included 50 blood samples from agematched (mean age $=70$ ) males with no known history of cancer.

All samples were collected after signing an informed consent which was approved by the Research and Ethics Committee at Yarmouk University and IRB approval from King Abdullah University Hospital at Jordan University of Science and Technology.

\section{DNA Extraction}

DNA was extracted from (FFPE) by using the QIAmp extraction DNA kit (Qiagen GmbH, Hilden, Germany) according to the manufacturer's protocols. Briefly, four to six sections of FFPE tissue were deparaffinized three times with $1 \mathrm{~mL}$ of Xylene, followed by three times wash with absolute ethanol. The samples then were incubated overnight at $56{ }^{\circ} \mathrm{C}$, with proteinase $\mathrm{K}$ lysis buffer, followed by incubation at $90^{\circ} \mathrm{C}$ for 45 minutes. The lysate was transferred to the column, washed as requested in the protocol. Final elution of the DNA was performed by adding TE buffer and centrifugation at 12,000 g. All collected samples were stored at $-80^{\circ} \mathrm{C}$ until use.

\section{PCR AND SEQUENCING}

For the amplification of the target area, specific primers were requested as described before [16]: F-5'AGCTGGGAACTGCAACTCAT-3', R-5'-CGCCTCACACACTCACCTC-3' (IDT, Illinois, USA) (Figure 1). PCR reaction was conducted in a total volume of $30 \mathrm{~L}$ by using 2X-master-mix from (BioLabs, New England, USA) under the following conditions: Initial denaturation at $94{ }^{\circ} \mathrm{C}$ for 3 minutes, 40 cycles of denaturation, annealing and extension for 30 seconds at $94{ }^{\circ} \mathrm{C}, 60^{\circ} \mathrm{C}$ and $68^{\circ} \mathrm{C}$, respectively. Followed by final extension was at $68^{\circ} \mathrm{C}$ for 5 minutes. The PCR products were analyzed and resolved by running the samples on $1.5 \%$ agarose gel.

Sanger DNA sequencing was analyzed as an external service by (GENEWIZ, NJ, USA). The output DNA sequencing service was analyzed by UGENE software.

\section{Statistical Analysis}

GraphPad Prism 6 software was used to calculate the p-value, Hardy-Weinberg Equilibrium HWE, the odd ratio (OR) and $95 \%$ confidence interval (CI) by performing
Clinicopathological data of the patients

Table 1

\begin{tabular}{|l|c|c|}
\hline \multicolumn{3}{|c|}{ Clinicopathological data $(n=72 \pm 10.5)$} \\
\hline Age (years) & 72 & \\
\hline PSA (ug/L) & 61.6 & $\%$ \\
\hline Gleason Score & $n$ & 13 \\
\hline $3+3$ & 10 & 25 \\
\hline $3+4$ & 20 & 4 \\
\hline $4+3$ & 3 & 13 \\
\hline $4+4$ & 10 & 26 \\
\hline $4+5$ & 21 & 4 \\
\hline $5+4$ & 3 & 15 \\
\hline $5+5$ & 12 & \\
\hline
\end{tabular}

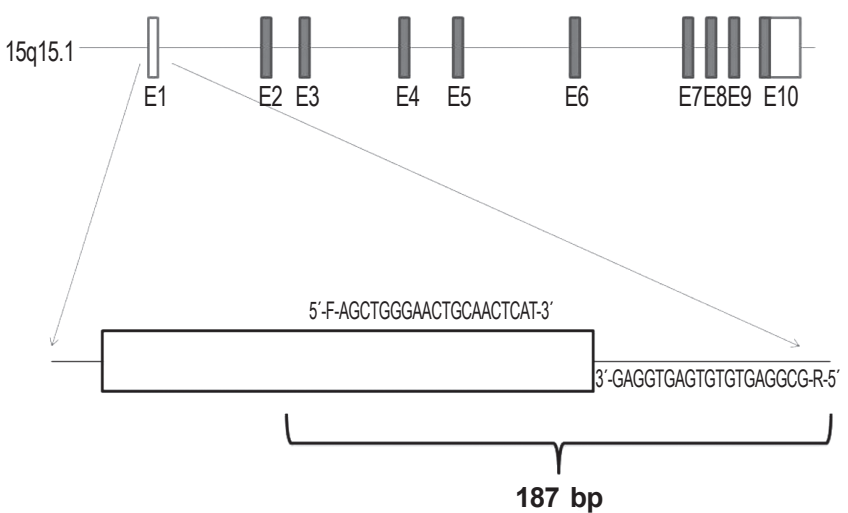

Fig. 1. Illustration of $R A D 51$ gene describing the location of the target area on chromosome 15 including 10 exons. The primers positions and the expected product size (187 bp) are shown. The amplified area is including part of exon 1 and intron 1

Chi-square test and Fisher's exact test. $\mathrm{P}$ value considered significant when it is $<0.05$.

\section{RESULTS}

Genotypes frequencies of $135 \mathrm{G}>\mathrm{C}$ ( $\mathrm{rs} 1801320)$

PCR product was resolved by $1.5 \%$ agarose to confirm the amplification of the product of $187 \mathrm{bp}$ (Figure 2).

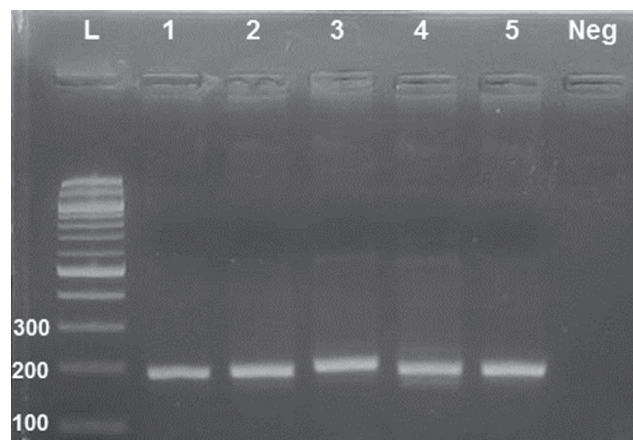

Fig. 2. A representative gel electrophoresis for the PCR product of the target sequence located in the 5 '-UTR area of the RAD51 gene. Lane L: 100 bp marker, Lanes 1-5 positive product and Lane Neg: Negative control 

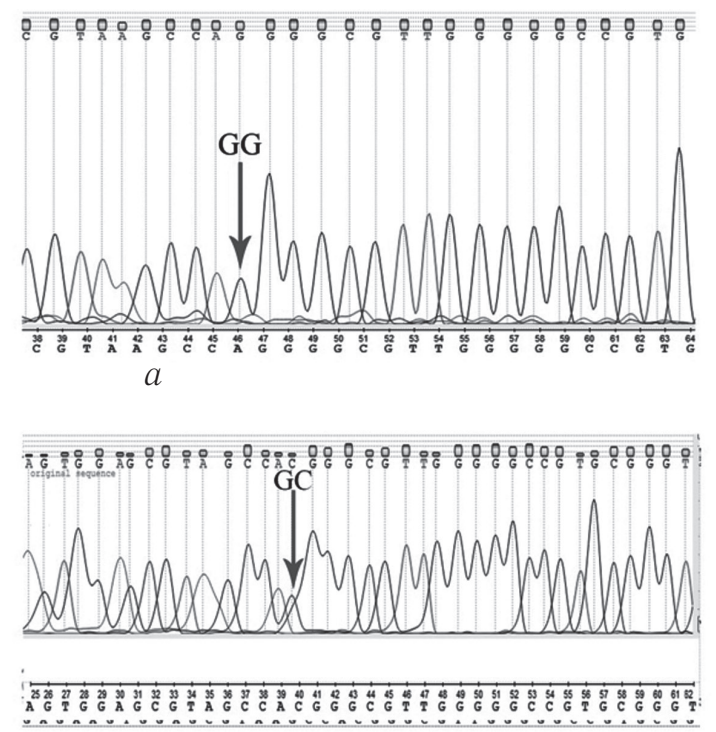

b

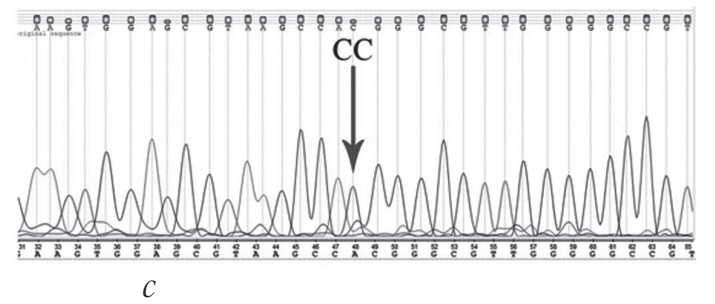

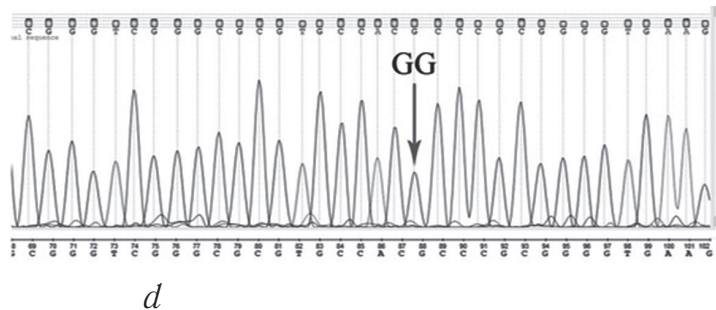
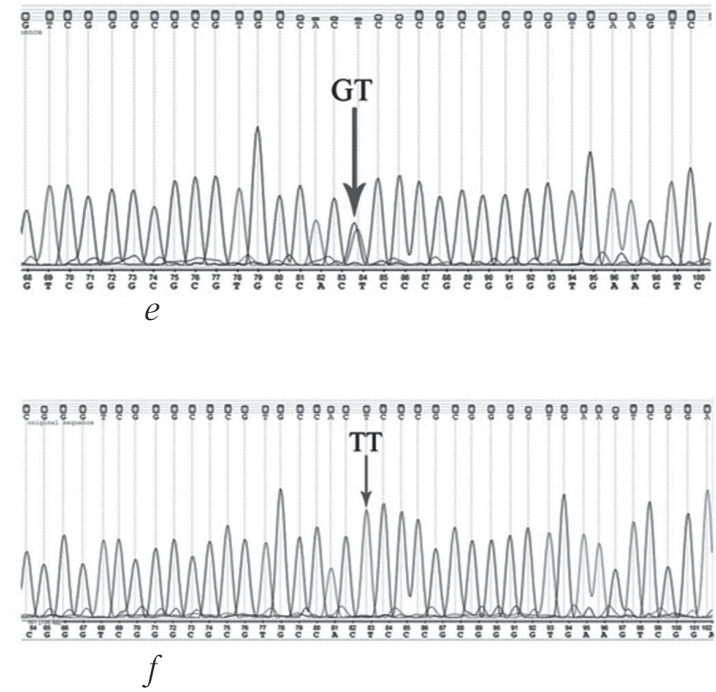

Fig. 3. Chromatogram of the target sequences in the 5'-UTR-RAD51 area. $a, b$ and $c$ represent the GG, GC and CC genotypes of the rs $1801320 \mathrm{G}>$ C polymorphism. $d, e$ and $f$ represent the GG, GT and TT genotypes of the rs $1801321 \mathrm{G}>\mathrm{T}$ polymorphism

Percentage distribution of rs 1801320 (G135C) genotypes in prostate cancer (PC) cases and control group, showing a significant difference between prostate cancer cases and control group

\begin{tabular}{|c|l|c|c|c|c|c|}
\hline \multirow{5}{*}{ Ss1801320 } & Tumors & $\%$ & Control & $\%$ & \\
\cline { 2 - 7 } & G135G & 74 & 92.5 & 44 & 88.0 & 10.0 \\
\cline { 2 - 7 } & G135C & 1 & 1.3 & 5 & 2.0 & $X^{2}=6.041$, \\
\cline { 2 - 7 } & C135C & 5 & 6.2 & 1 & 100 & \\
\cline { 2 - 7 } & Total & 80 & 100 & 50 & \\
\hline
\end{tabular}

In the study population, there was no significant difference in the mean age between patients and control group, 72 and 70 years, respectively. The clinicopathological data showed the distribution of Gleason score between $3+3$ and $5+5$ and PSA concentration (mean $61.6 \mu \mathrm{g} / \mathrm{L}$ ) (Table 1). The sequences of the target SNPs in the 5'-UTR area of the RAD51 gene were confirmed by Sanger sequencing and shown in (Figure 3 ). The genotypes frequencies of the rs $1801320 \mathrm{G}>\mathrm{C}$ polymorphism in the patients group showed the following distribution: the homozygous G135G variant was $74(92.5 \%)$, the heterozygous $\mathrm{G} 135 \mathrm{C}$ variant was $1(1.3 \%)$ and the homozygous $\mathrm{C} 135 \mathrm{C}$ variant was $5(6.2 \%)$ and shown in (Table 2). While the control group showed the follow- ing distribution of the G135C genotypes: the homozygous G135G was $44(88 \%)$, the heterozygous G135C variant was $5(10 \%)$ and the homozygous C135C variant was $1(2 \%)$ and shown in (Table 2). Accordingly, our results showed a significant association between $135 \mathrm{G}>\mathrm{C}$ genotype and the presence of prostate cancer $\left(p=0.041 X^{2}=6.377\right)$. While the frequency of $\mathrm{C}$ allele did not show any significant association with the presence of prostate cancer ( $p=1.0$ and $\mathrm{OR}=0.9895 \% \mathrm{CI}$ : (0.3671 to 2.620$)$ ).

Genotypes frequencies of $172 \mathrm{G}>\mathrm{T}$ ( $\mathrm{rs} 1801321)$

In the patient group, the rs1801321 G>T genotypes frequencies for the homozygous G172G, heterozygous G172T and homozygous T172T variants were $17(21.25 \%), 53(66.25 \%)$ and $10(12.5 \%)$, respective- 
Table 3

Percentage distribution of rs 1801321 (G172T) genotypes in prostate cancer (PC) cases and control group, showing no significant difference between prostate cancer cases and control group

\begin{tabular}{|l|l|c|c|c|c|c|}
\hline \multirow{5}{*}{ rs1801321 } & \multicolumn{1}{|c|}{ SNP } & Tumors & $\%$ & Control & $\%$ & \\
\cline { 2 - 7 } & G172G & 17 & 21.25 & 15 & 30.0 & \\
\cline { 2 - 7 } & G172T & 53 & 66.25 & 26 & 52.0 & 18.0 \\
\cline { 2 - 7 } & T172T & 10 & 12.5 & 9 & 100 & 2.6 \\
\cline { 2 - 7 } & Total & 80 & 100 & 50 & \\
\hline
\end{tabular}

ly (Table 3). While the control group showed the following distribution of the G135C genotypes: the homozygous G172G variant was $15(30 \%)$, the heterozygous G135C variant was $26(52 \%)$ and the homozygous $\mathrm{C} 135 \mathrm{C}$ variant was $9(18 \%)$ and shown in (Table 3$)$. For the 172 $\mathrm{G}>\mathrm{T}$ polymorphism, our results did not show any significant association between $172 \mathrm{G}>\mathrm{T}$ genotypes $(p=0.27$, $X^{2}=2.6$ ) or allelic frequencies and the susceptibility of prostate cancer in the study population $(p=0.89$ $\mathrm{OR}=1.0795 \% \mathrm{CI}$ : (0.6459 to 1.766$)$ ).

\section{DISCUSSION}

The current study aimed to evaluate the association between the polymorphisms of 5'-UTR of RAD51 gene and the development of prostate cancer. Our results showed a significant association between G135C variant (rs1801320) and the development of prostate cancer in the Jordanian population. On the other hand, neither the G172T variant nor $T$ allele frequency showed any significant association with the susceptibility of prostate carcinoma. These results are consistent with the previous findings by Nowacka et al [19].

A number of DNA repairing genes have been studied to find an association with the risk of prostate cancer. However, from the long list of investigated genes, few variants in those genes are associated with development or prognosis of prostate cancer $[40,41]$. In many previous reports, an association was demonstrated between the 5'-UTR polymorphisms of RAD51 gene and the susceptibility of breast cancer $[12,16]$. Therefore, we aimed to evaluate a possible role of these variants in the development of prostate cancer. In addition, RAD51 overexpression has been demonstrated in high-grade prostate cancer [42]. Moreover, mRNA and protein levels of RAD51 and other homologous recombination-related proteins were elevated in malignant prostate cancer cell line [43].

The impact of G135C variant (rs1801320) on the development of cancer is not fully understood. However, a functional study has shown higher expression of the RAD51 protein by replacement of $\mathrm{G}$ with $\mathrm{C}$ at position 135 and $\mathrm{G}$ with $\mathrm{T}$ at position 172 of the 5'-UTR area of RAD51 gene [44]. Those findings, hypothetically, proposed a crucial impact of RAD51 overexpression in the development of prostate cancer as well as many other cancers. Regardless of the molecular mechanism of the effect of the overexpression of RAD51, the DNA repair system is supposed to lessen the risks of mutations that are generated from environmental risk factors, which speculates a positive impact of RAD51 expression. This dilemma requires a full understanding of the mechanism of RAD51 during DNA repair. Partial resolution of BRCA2 and RAD51 repairing mechanism was described by Lord et al, they described two different sites (motifs) within BRCA2 that bind different forms of RAD51, which may require a balance between this interaction for proper function of the BRCA2-RAD51 complex in DNA repair [10]. This may explain the possible negative impact of RAD51 overexpression in some cancers. Pieces of evidence are accumulated about the role of RAD51 overexpression in different cancers, besides the association between the 5'-UTR polymorphisms and the susceptibility of cancer [12, 15, 16, 18-21, 31, 32, 36-38, 42]. More functional studies are required to understand the role of RAD51 during the pathogenesis of cancer. Our findings do not exclude the impact of environmental risk factors and other genetic alterations in the development of prostate cancer. However, we highlight the possible contribution of $5^{\prime}-U T R-R A D 51$ variants in the development of prostate cancer.

In conclusion, our results underscore the possible association between G135C variant (rs1801320) and the susceptibility of prostate cancer in the Jordanian population. More large-scale studies are required to elucidate the role of G135C variant (rs 1801320) and RAD51 expression in the development of prostate cancer.

Acknowledgments: We would like to thank Mr. Nidal Ghanem from KAUH and Mr. Adel Rababah for their assistance. This work was funded by the Deanship of Scientific Research and Graduate Studies at Yarmouk University, Grant No: 12/2015

Conflicts of interest: No potential conflicts of interest were disclosed.

\section{REFERENCES}

1. Abuadas MH, Petro-Nustas W, Albikawi ZF. Predictors of Participation in Prostate Cancer Screening among Older Men in Jordan. Asian Pac J Cancer Prev 2015;16(13): 5377-83. doi: 10.7314/apjcp.2015.16.13.5377. 
2. Nupponen NN, Carpten JD. Prostate cancer susceptibility genes: many studies, many results, no answers. Cancer Metastasis Rev. 2001;20(3/4):155-164. doi: 10.1023/a:1015557308033.

3. Simard J. Prostate cancer susceptibility genes: lessons learned and challenges posed. Endocr Relat Cancer. 2003;10(2):225-259. doi: 10.1677/erc.0.0100225.

4. Ostrander EA, Johannesson B. Prostate Cancer Susceptibility Loci: Finding the Genes. In: JJ Li, SA Li, Mohla S, et al, editors. Hormonal Carcinogenesis V. Advances in Experimental Medicine and Biology. Vol 617. New York: Springer; 2008. p. 179-190. doi: 10.1007/978-0387-69080-3_17.

5. Edwards SM, Kote-Jarai Z, Meitz J, et al. Two Percent of Men with Early-Onset Prostate Cancer Harbor Germline Mutations in the BRCA2 Gene. Am J Hum Genet. 2003;72(1):1-12. doi: 10.1086/345310.

6. Agalliu I, Kwon EM, Zadory D, et al. Germline mutations in the BRCA2 gene and susceptibility to hereditary prostate cancer. Clin Cancer Res. 2007;13(3):839-43. doi: 10.1158/1078-0432.CCR-06-2164.

7. Gallagher DJ, Gaudet MM, Pal P, et al. Germline BRCA mutations denote a clinicopathologic subset of prostate cancer. Clin Cancer Res. 2010;16(7):21152121. doi: 10.1158/1078-0432.CCR-09-2871.

8. Zhang XJ, Liu P, Zhu F. Polymorphisms of DNA repair-related genes with susceptibility and prognosis of prostate cancer. Genet Mol Res. 2014;13(2):4419-24. doi: 10.4238/2014.January.24.20.

9. Wood RD, Mitchell M, Sgouros J, Lindahl T. Human DNA repair genes. Science. 2001;291(5507):1284-9. doi: 10.1126/science. 1056154.

10.Lord CJ, Ashworth A. RAD51, BRCA2 and DNA repair: a partial resolution. Nat Struct Mol Biol. 2007;14(6):461 -462. doi: 10.1038/nsmb0607-461.

11. Majidinia $M$, Yousefi B. DNA repair and damage pathways in breast cancer development and therapy. DNA Repair (Amst). 2017;54:22-29. doi: 10.1016/j. dnarep.2017.03.009.

12.Al Zoubi MS, Zavaglia K, Mazanti C, et al. Polymorphisms and mutations in GSTP1, RAD51, XRCC1 and XRCC3 genes in breast cancer patients. Int J Biol Markers. 2017;32(3):e337-e343. doi: 10.5301/ijbm.5000258.

13. Tulbah S, Alabdulkarim H, Alanazi M, et al. Polymorphisms in RAD51 and their relation with breast cancer in Saudi females. Onco Targets Ther. 2016;9:269-277. doi: 10.2147/OTT.S93343.

14. Trang TT, Nagashima H, Uchida T, et al. RAD51 G135C genetic polymorphism and their potential role in gastric cancer induced by Helicobacter pylori infection in Bhutan. Epidemiol Infect. 2016;144(2):234-40. doi: 10.1017/S0950268815001430.

15. Krivokuca AM, Cavic MR, Malisic EJ, et al. Polymorphisms in cancer susceptibility genes XRCC1, RAD51 and TP53 and the risk of breast cancer in Serbian women. Int J Biol Markers. 2016;31(3):e258-263. doi: $10.5301 / \mathrm{jbm} .5000201$.

16.Al-Zoubi MS, et al. Homozygous T172T and Heterozygous G135C Variants of Homologous Recombination Repairing Protein RAD51 are Related to Sporadic Breast Cancer Susceptibility. Biochem Genet. 2016;54( 1):83-94. doi: 10.1007/s 10528-015-9703-z.

17. Sekhar D, Pooja S, Kumar S, Rajender S. RAD51 135G >C substitution increases breast cancer risk in an ethnic-specific manner: a meta-analysis on 21,236 cases and 19,407 controls. Sci Rep. 2015;5:11588. doi: 10.1038/srep1 1588.

18. Pelttari LM, Kiiski JI, Ranta S, et al. RAD51, XRCC3, and XRCC2 mutation screening in Finnish breast cancer families. Springerplus. 2015;4:92. doi: 10.1186/ s40064-015-0880-3.

19. Nowacka-Zawisza M, Wisnik E, Wasilewski A, et al. Polymorphisms of homologous recombination RAD51, RAD51B, XRCC2, and XRCC3 genes and the risk of prostate cancer. Anal Cell Pathol (Amst). 2015;2015:828646. doi: 10.1155/2015/828646.

20.Hu X, Sun S. RAD51 Gene $135 G / C$ polymorphism and ovarian cancer risk: a meta-analysis. Int J Clin Exp Med. 2015;8(12):22365-22370.

21. Cetinkunar S, Gok I, Celep RB, et al. The effect of polymorphism in DNA repair genes RAD51 and XRCC2 in colorectal cancer in Turkish population. Int J Clin Exp Med. 2015;8(2):2649-2655.

22. Maacke H, Opitz S, Jost K, et al. Over-expression of wildtype RAD51 correlates with histological grading of invasive ductal breast cancer. Int J Cancer. 2000;88(6):907-13. doi: $\quad$ 10.1002/1097-0215(20001215)88:6<907::aidijc1 $1>3.0$. co;2-4.

23. Maacke H, Jost K, Opitz S, et al. DNA repair and recombination factor RAD51 is over-expressed in human pancreatic adenocarcinoma. Oncogene. 2000;19(23):2791 -2795. doi: 10.1038/sj.onc. 1203578.

24. Kato M, Yano K, Matsuo F, et al. Identification of RAD51 alteration in patients with bilateral breast cancer. J Hum Genet. 2000;45(3):133-137. doi: 10.1007/ s100380050199.

25. Thomas G, Jacobs KB, Kraft P, et al. A multistage genome-wide association study in breast cancer identifies two new risk alleles at 1 p 11.2 and 14q24.1 (RAD51L1). Nat Genet. 2009;41(5):579-584. doi: 10.1038/ng.353.

26. Li Y, Wang WY, Xiao JH, et al. Overexpression of RAD51 Predicts Poor Prognosis in Colorectal Cancer: Our Experience with 54 Patients. PLoS One. 2017;12(1):e0167868. doi: 10.1371/journal.pone.0167868.

27. Thompson LH, Schild D. Recombinational DNA repair and human disease. Mutat Res. 2002;509(1-2):49-78. doi: 10.1016/s0027-5107(02)00224-5.

28.Stark JM, Pierce AJ, Oh J, et al. Genetic steps of mammalian homologous repair with distinct mutagenic consequences. Mol Cell Biol. 2004;24(21):9305-9316. doi: 10.1128/MCB.24.21.9305-9316.2004. 
29. Paffett KS, Clikeman JA, Palmer S, Nickoloff JA. Overexpression of RAD51 inhibits double-strand break-induced homologous recombination but does not affect gene conversion tract lengths. DNA Repair (Amst). 2005;4(6):687-698. doi: 10.1016/j.dnarep.2005.03.003.

30. Brown ET, Holt JT. RAD51 overexpression rescues radiation resistance in BRCA2-defective cancer cells. Mol Carcinog. 2009;48(2):105-109. doi: 10.1002/ mc.20463.

31. Ricks-Santi LJ, Sucheston LE, Yang Y, et al. Association of RAD51 polymorphism with DNA repair in BRCA1 mutation carriers and sporadic breast cancer risk. BMC Cancer. 2011;11:278. doi: 10.1186/1471-2407-11-278.

32. Li W, Liu KJ, Song JS, et al. Association between RAD51 polymorphism and breast cancer susceptibility: a meta analysis. Int J Clin Exp Med. 2015;8(2): 2326-2333.

33. Al Zoubi MS. X-ray repair cross-complementing protein 1 and 3 polymorphisms and susceptibility of breast cancer in a Jordanian population. Saudi Med J. 2015;36(10):11631167. doi: 10.15537/smj.2015.10.12659.

34. Auranen A, Song H, Waterfall C, et al. Polymorphisms in DNA repair genes and epithelial ovarian cancer risk. Int J Cancer. 2005;117(4):611-8. doi: 10.1002/ijc.21047.

35. Poplawski T, Arabski M, Kozirowska D, et al. DNA damage and repair in gastric cancer - a correlation with the hOGG1 and RAD51 genes polymorphisms. Mutat Res. 2006;601(1-2):83-91. doi: 10.1016/j. mrfmmm.2006.06.002.

36. Jakubowska A, Gronwald J, Menkiszak J, et al. The RAD51 $135 \mathrm{G}>\mathrm{C}$ polymorphism modifies breast cancer and ovarian cancer risk in Polish BRCA1 mutation carriers. Cancer Epidemiol Biomarkers Prev. 2007;16(2):270-275. doi: 10.1158/1055-9965.EPI-06-0562.
37. Parvin S, Islam MS, Al-Mamun MM, et al. Association of BRCA1, BRCA2, RAD51, and HER2 gene polymorphisms with the breast cancer risk in the Bangladeshi population. Breast Cancer. 2017;24(2):229-237. doi: 10.1007/s12282-016-0692-5.

38. Cheng D, Shi H, Zhang K, et al. RAD51 Gene 135G/C polymorphism and the risk of four types of common cancers: a meta-analysis. Diagn Pathol. 2014;9:18. doi: 10.1186/1746-1596-9-18.

39. Dhillon VS, Yeoh E, Fenech M. DNA repair gene polymorphisms and prostate cancer risk in South Australia results of a pilot study. Urol Oncol. 2011;29(6):641-6. doi: 10.1016/j.urolonc.2009.08.013.

40. Park JY, Huang Y, Sellers TA. Single nucleotide polymorphisms in DNA repair genes and prostate cancer risk. Methods Mol Biol. 2009;471:361-385. doi: 10.1007/978-1-59745-416-2_18.

41. Henriquez-Hernandez LA, Valenciano A, Foro-Arnalot $\mathrm{P}$, et al. Single nucleotide polymorphisms in DNA repair genes as risk factors associated to prostate cancer progression. BMC Med Genet. 2014;15:143. doi: 10.1186/s12881-014-0143-0.

42. Mitra A, Jameson C, Barbachano Y, et al. Overexpression of RAD51 occurs in aggressive prostatic cancer. Histopathology. 2009;55(6):696-704. doi: 10.1111/j.1365-2559.2009.03448.x.

43. Bristow RG, Ozcelik H, Jalali F, et al. Homologous recombination and prostate cancer: a model for novel DNA repair targets and therapies. Radiother Oncol. 2007;83(3):220-230. doi: 10.1016/j.radonc.2007.04.016.

44. Hasselbach L, Haase S, Fischer D, et al. Characterisation of the promoter region of the human DNA-repair gene RAD51. Eur J Gynaecol Oncol. 2005;26(6):589-598.

(8) Information about the authors

Mazhar Salim Al-Zoubi - Department of Basic Medical Sciences, Faculty of Medicine,
Yarmouk University, Irbid, Jordan. E-mail: mszoubi@yu.edu.jo.
Khalid Al-Batayneh - Department of Biological Sciences, Faculty of Science, Yarmouk
University, Irbid, Jordan. E-mail: albatynehk@yu.edu.jo.
Bahaa Al-Trad - Department of Biological Sciences, Faculty of Science, Yarmouk University,
Irbid, Jordan. E-mail: bahaa.tr@yu.edu.jo.
Mohammed Alorjani - Department of Pathology, Faculty of Medicine, Jordan University of
Science and Technology, Irbid, Jordan. E-mail: msalorjani@just.edu.jo.
Samir Al-Bashir - Department of Pathology, Faculty of Medicine, Jordan University of Science
and Technology, Irbid, Jordan. E-mail: samer94@hotmail.com.
Raed M. Al-Zoubi - Department of Chemistry, Jordan University of Science and Technology,
Irbid, Jordan. E-mail: rmzoubi@just.edu.jo.
Sohaib M. Al-Khatib - Department of Pathology, Faculty of Medicine, Jordan University of
Science and Technology, Irbid, Jordan. E-mail: smkhatib4@just.edu.jo.
Mohammad Al-Hamad - Department of Pathology, College of Medicine, Imam Abdulrahman
Bin Faisal University (IAU), Dammam, Kingdom of Saudi Arabia. E-mail: mhamad@iau.edu.sa.
Mutaz A. Abd Al-Razaq - Department of Biological Sciences, Faculty of Science, Yarmouk
University, Irbid, Jordan. E-mail: mutaz.a@yu.edu.jo.
Riyad Muhaidat - Department of Biological Sciences, Faculty of Science, Yarmouk University,
Ismail, Jordan. E-mail: muhaidat@yu.edu.jo.

